\title{
An Asia Pacific Alliance for Rare Diseases
}

\author{
Durhane Wong-Rieger • William Claxton • \\ Richard Vines · Carmencita Padilla • \\ Kin Ping Tsang $\cdot$ Lucy Hickinbotham
}

Published online: 18 December 2014

(C) Springer International Publishing Switzerland 2014

\section{Introduction}

Rare disease organizations representing small patient populations have had great impact in helping to secure orphan drug and rare disease legislation by joining forces, in the USA as a national alliance (National Organization for Rare Disorders) and in Europe as a regional alliance (European Organization for Rare Disorders), with a focus on affecting policy [1-3]. In the rest of the world, rare disease alliances have been slower to form and, for the most part, have had less visible impact on national policy. Notable exceptions are patient associations in Taiwan and Japan in the Asia-Pacific region and very recently the alliance in Colombia in Latin America. Through regional and international rare disease conferences and forums, rare disease associations have had opportunities to meet, to discuss common concerns, and to acknowledge their limited individual resources but potentially 'significant'

\author{
D. Wong-Rieger $(\bowtie)$ \\ Canadian Organization for Rare Disorders, Toronto, Canada \\ e-mail: durhane@sympatico.ca \\ W. Claxton \\ CNETS Singapore, Singapore, Sigapore \\ R. Vines \\ Rare Cancers Australia, Bowral, Australia \\ C. Padilla \\ Philippine Society for Orphan Disorders, San Juan, Philippines \\ K. P. Tsang \\ Retina Hong Kong, Hong Kong, China \\ L. Hickinbotham \\ Novartis Asia Pacific Pharmaceuticals Pte. Ltd, Singapore, \\ Singapore
}

collective capabilities. This paper reports on an initiative to establish an alliance of Asia-Pacific organizations, building on the efforts of national alliances and disease-specific groups in each country, with the collective goal of influencing rare disease policy and practice throughout the region.

\section{Impact of National and Regional Rare Disease Patient Organizations}

\subsection{Why National and Regional Rare Disease Patient Organizations?}

Across nations, despite variations in prevalence numbers, a 'common' definition of a rare disease is a "condition that affects a small patient population" [4-6]. Moreover, while organizations serving a single rare condition may be very small and have limited influence on national policy, an alliance of groups representing even a fraction of the 7,000 known rare diseases [7] can be very impactful. The National Organization for Rare Disorders (NORD) and the European Organization for Rare Disorders (EURORDIS) were instrumental in the successful passage of orphan drug legislation in the USA and the EU, respectively [8-10]. The Canadian Organization for Rare Disorders has played an analogous role in advocating for Canadian regulators to bring in comparable regulations [11]. According to EURORDIS, national alliances are [12]:

- able to advocate for all rare disease patients at a national level and constitute a powerful stakeholder that governments must take into account

- better listened to because they represent a group of patient associations 
- able to take part in the policy development or decisionmaking process

- gaining political influence and social recognition for rare disease patients and families.

\subsection{National Alliances in Taiwan, Japan, and South Korea}

In the Asia-Pacific region, some rare disease alliances comprised patient groups but many more represent individuals (affected by various diseases). Across all alliances, the common activities are advocacy and public awareness; a primary advocacy focus is improved healthcare services (screening, diagnosis, treatment, and support) with comparatively less emphasis on research and/or drug development. In three countries (Japan, Taiwan, and South Korea), policies to foster orphan drug research and development have emerged independently and often precede the formation of national patient alliances. Table 1 provides a summary of rare disease alliances in the Asia-Pacific region, including the activities, type of membership, and year founded, plus a brief overview of the status of orphan drug and/or rare disease policy in each country and any other resources for rare diseases.

\section{Proposed Asia-Pacific Alliance for Rare Disease}

\subsection{Outcomes of International and Regional Networking}

One path of development for rare disease organizations in smaller and 'less developed' countries has been participation in international disease associations. A prime example is the 50-year-old World Federation of Hemophilia, which sponsors a twinning program that links national organizations or treatment centers often in a 'more developed' and a 'lesser developed' country [13]. The Carcinoid-Neuroendocrine Tumour Society (Singapore) was formed through partnership with the eponymous Canadian organization and now supports patients throughout the Asia-Pacific region [14]. National alliances have also been the 'organic' coalescence of individuals and families affected by different diseases with common challenges. This second pathway was the route taken by two parents in Taiwan who, in 1998, combined efforts to provide mutual support, raise public awareness, and to create a strong advocacy voice. The Taiwan Foundation for Rare Disorders, which comprises both patient groups and individuals, is credited with Taiwan's adoption of the 2000 Rare Disease and Orphan Drug Act, the scope of which far exceeds those of both the American and European Acts [15, 16]. The Japan Patient
Association represents a third form of alliance building, whereby the Japanese government had already enacted orphan drug and rare disease policy, but the patient voice was not strongly represented. By joining together, the patient groups could play a more effective role on behalf of all patients [17].

As noted in Table 1, there is considerable disparity across the region in terms of orphan drug and rare disease policy, reflecting-to some degree-different levels of economic development, healthcare coverage, and patient engagement. A number of factors stimulated the interest in an Asia-Pacific alliance of rare disease organizations. As noted previously, many groups became aware of each other virtually through social media and especially through participation in Rare Disease Day activities posted on the EURORDIS Rare Disease Day website and Facebook. They met not only in international disease-specific environments but also in cross-disease forums, including conferences hosted by EURORDIS and ICORD (International Congress on Rare Diseases). From a number of separate meetings and conversations, patient groups in the Asia-Pacific region began to explore the possibility of creating a regional alliance with a collective patient voice that could help leverage awareness and action in each of their countries.

It was also encouraging to know that, across the Pacific, efforts to form a regional alliance for rare diseases in Latin America, the Geiser Fundación, had been underway since 2002. There have been incremental successes; for example, there are laws supporting rare diseases in five countries: Argentina, Mexico, Colombia, Peru, and Brazil [18]. In 2013, ALIBER, an alliance of Spanish and Portuguesespeaking groups spanning the Atlantic, was formalized [19].

The need for collective action echoes the multi-stakeholder 'call to action' for improved access to care and treatment for rare diseases in the Asia-Pacific region [20]. In October 2012, patient advocates from across the AsiaPacific region representing rare diseases and rare cancers met in Singapore to discuss common challenges and to consider collaboration at a regional level, with the goals of not only providing a forum for sharing experiences and learning but also increasing their voice and addressing priority issues. Invitations were sent to patient groups known to the organizers as active participants in regional or national activities, asking about their interest in exploring the formation of a rare disease alliance. The 15 participants who attended represented 12 organizations from seven countries. Some were members of disease-specific groups, others were from societies for rare diseases or rare cancers in general, and others represented patient group alliances or networks. Logistical and funding support was provided by Novartis Asia Pacific Pharmaceuticals Pte. Ltd. A list of all participants is in Appendix 1. 


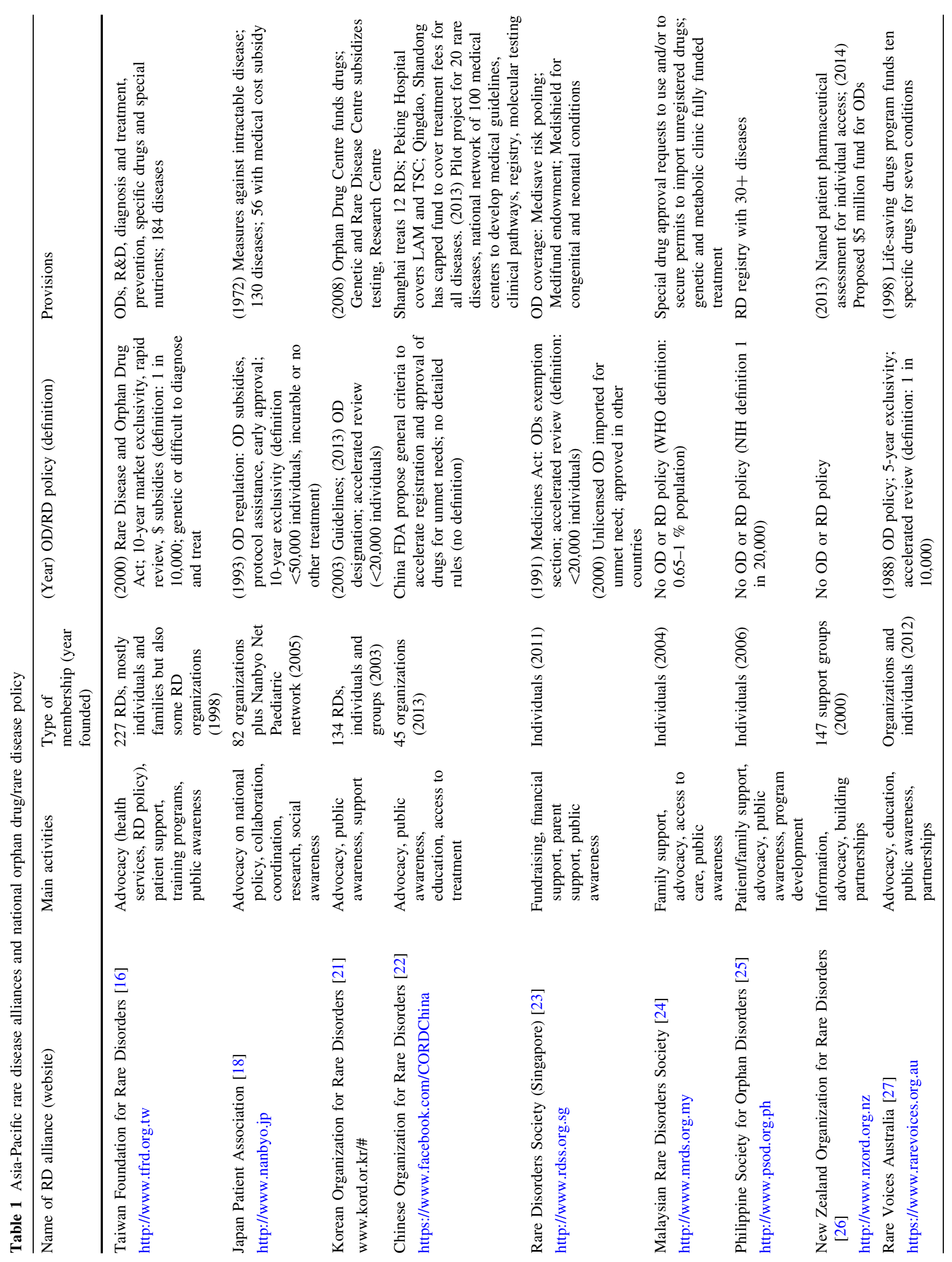




\subsection{Common Challenges}

As a basis for alliance building, the first goal of the meeting was to identify common challenges faced by individuals with rare disorders and rare cancers. The common patient issues were grouped as follows: lack of access to state-of-the-art care, lack of quality information, and lack of public awareness and policies. For the first of these, a key problem is late diagnosis compounded by lack of genetic counseling, pre-natal screening, and advanced newborn screening for metabolic and other congenital conditions. Many countries have few specialists and these are inaccessible to patients in remote locations. There is a lack of health insurance, in general, and limited reimbursement for drugs, which means most treatments are unavailable unless there is a compassionate access program. Finally, there are few support groups, and the social stigma attached to some (rare) diseases makes it difficult for patients to reach out.

The second common challenge identified was the lack of rare disease registries, which undermines efforts to demonstrate the prevalence of rare diseases as well as the seriousness of the problem. This, in turn, leads to the third common challenge: the lack of prioritization of rare diseases as a public health issue. Finally, lack of public awareness diminishes willingness to allocate resources for research, prevention, diagnosis, treatment, and support.

\subsection{Actions}

The participants agreed there was mutual benefit from working collectively to leverage support internationally towards the following outcomes: to define and map the burden of rare diseases (in the region); to empower regional leaders and healthcare providers with knowledge and skills; to promote collection of patient data accessible in public domain registries; to promote access to prevention, diagnosis, and treatment; to identify and create (regional) networks of reference; to promote the use of telemedicine and tele-genetics for rare diseases; and to raise awareness among healthcare providers and the public. Participants agreed a regional alliance would be valuable.

In February 2014, a second regional forum was held in Singapore with some of the previous and some new participants (11 participants from seven countries). The group started by articulating the purposes of a regional alliance of rare disease organizations, as follows:

- Helping to act on common or parallel authorities to promote best practice.

- Promoting collaboration in research and mutual learning initiatives. 
- Working together to achieve common goals, to share resources and learning to enhance activities of the member organizations.

A proposed name and draft vision statement were developed. Activities proposed for the alliance included facilitating access to medicines; collaborating with physicians, researchers, professional associations, policy makers, and regulators; increasing public awareness; and developing a database of specialist centers. The alliance also identified the benefits of a common definition of rare disease in the region. Finally, as a patient-led advocacy initiative, the alliance will be able to collaborate with other national and regional alliances, including those in Europe, North America, and Latin America.

However, participants identified that the first tasks were to formally establish the alliance, promote its formation, develop a solid membership base, and secure resources to support the operation of the alliance.

\subsection{Steering Committee Organizational Meeting}

To move toward a formal entity, a number of teleconferences and a planning meeting were held to organize a faceto-face steering committee meeting during the International Rare Disease Research Consortium conference in Shenzhen, China in November 2014. The 4-h session included representatives from the Chinese Organization for Rare Disorders, the Japan Patient Association, the Indian Organization for Rare Disorders, New Zealand Organization for Rare Disorders, Rare Voices Australia, and CNETS (Carcinoid and Neuroendocrine Tumor Society) Singapore and was facilitated by the representative from the Canadian Organization for Rare Disorders. The Steering Committee agreed to the following outcomes:

- Name: Asia-Pacific Alliance of Rare Disease Organizations (APARDO) to be established as a legal entity (company limited by guarantee, filed in Singapore).

- Vision: To be a strong united voice in the Asia-Pacific region on behalf of patients and families [living with]/ [affected by] rare diseases.

- Objectives:

- Larger voice on rare diseases by integrating our voices

- Sharing information through active communications

- Policy development for regional policies and national policies

- Conduit for developing rare disease national alliances by connecting groups
- Capability (capacity) building to improve advocacy and access

- Mission and Mandate: To help member organizations improve treatment outcomes for those affected by rare diseases (including rare cancers) in Asia-Pacific.

- Membership criteria (inclusive rather than exclusive)

- National alliances

- Patient-led (but also joint membership) organizations

- National disease-specific organizations

- Others may be considered on a case-by-case basis.

The meeting concluded with a vision for 2015 and priorities to be accomplished, namely a survey to all rare disease groups in the region, website, two forums, and regular communications.

\section{Conclusion}

The formation of the Asia-Pacific Alliance for Rare Disease Organizations marks the opportunity for patient groups representing rare diseases and rare cancers to work together on common goals, facilitating research in the region, sharing resources and best practices, and collaborating on joint initiatives. While APARDO will not have the advantages of NORD or EURORDIS, whose members are united by a common regulator in their respective country or region, there is nevertheless the opportunity to work toward harmonization of policies and practices and establishing regional centers for research, diagnosis, and treatment. To those ends, APARDO members can call for harmonized orphan drug designation or mutual recognition across countries, as is the case with the US Food and Drug Administration and European Medicines Agency (despite variations in rare disease definitions). Moreover, all national alliances in the EU were able to take advantage of a common template and consultation process to work with internal stakeholders to develop national rare disease strategies. Alliances in non-EU countries have used the same process to fashion their own national strategies, and it would feasible for APARDO to adapt the tools for use in an Asia-Pacific context. Finally, APARDO can benefit from the learning and best practices of other international collaborations, disease-specific and cross-disease regional. For example, APARDO is adapting the "communication code" agreed to by the Latin American alliance HACERLA to ensure respectful, truthful, and timely communication. Next steps are formalization of the alliance, fundraising, and defining short-term achievable goals. 
Acknowledgments The authors would like to thank Kuan-Ju Chen (Taiwan Foundation for Rare Disorders), Dato Hatijah Binti Ayob (Malaysian Rare Disorders Society), Jirapon Chaimongkon (Thai CML Patient Group), Ulfana Umar (Indonesian Cancer Foundation), Lesley Murphy (Rare Voices Australia), and Hung-Ju Lin (Hope Foundation for Cancer Care) for their insight and contributions to this article.

Sources of support The alliance meetings in Singapore in 2012 and February 2014 were supported by Novartis Asia Pacific Pharmaceuticals Pte. Ltd. Other meetings were self-funded by participants.

\section{Appendix 1: APARDO Participants (October 2012, February and November 2014)}

Lesley Murphy, Rare Voices Australia

Kate Vines, Rare Cancers Australia

Richard Vines, Rare Cancers Australia

Durhane Wong Rieger, Canadian Organization for Rare

Disorders

Ulfana Umar, Indonesian Cancer Foundation

Kin Ping Tsang, Retina Hong Kong

Sylvia Harry Pumomo, Indonesian Cancer Foundation

Dato Hatijah Binti Ayob, Malaysian Rare Disorders Society

Maria Beatriz Gepte, Philippine Children's Medical Center

Carmencita Padilla, Philippine Society for Orphan

Disorders

William Claxton, Carcinoid and Neuroendocrine Tumor

Society (Singapore)

Panuwa, Thailand CML Foundation

Jirapon Chaimongkon, Thailand CML Foundation

Pipittaporn Vongpradit, Thailand CML Foundation

Kuan-ju Chen, Taiwan Foundation for Rare Disorders

Hung-Ju Lin, HOPE Foundation for Cancer Care, Taiwan

Lien-Ying Su, HOPE Foundation for Cancer Care, Taiwan

Tsui-er Wu, HOPE Foundation for Cancer Care, Taiwan

Cheng-Te Li, Taiwan Tuberous Sclerosis Complex Association

Jian-Ri Li, Taichung Urology Care Association, Taiwan

Kevin Wong, Chinese Organisation for Rare Diseases (CORD)

Yukiko Nishimura, International Relations, Japan Patient Association (JPA)

Ramiah Muthyala, Indian Organization for Rare Diseases (IORD)

Anna Kemble Welch, NZ Organisation for Rare Disorders (NZORD)

Ziyue Xu, Chinese Organisation for Rare Diseases (CORD)

\section{References}

1. Mavris M, Le CY. Involvement of patient organisations in research and development of orphan drugs for rare diseases in Europe. Mol Syndromol. 2012;3(5):237-43.
2. Pritchard-Jones K, Pieters R, Reaman GH, Hjorth L, Downie P, Calaminus G, et al. Sustaining innovation and improvement in the treatment of childhood cancer: lessons from high-income countries. Lancet Oncol. 2013;14(3):e95-103.

3. Taruscio D, Gentile AE, De SM, Ferrelli RM, de la Posada PM, Hens M, et al. EUROPLAN: a project to support the development of national plans on rare diseases in Europe. Public Health Genomics. 2013;16(6):278-87.

4. Orphanet. About rare diseases. 2014. http://www.orpha.net/consor/ cgi-bin/Education_AboutRareDiseases.php?lng=EN. Accessed 10 June 2014.

5. Mazzucato M, Visona Dalla PL, Manea S, Minichiello C, Facchin $P$. A population-based registry as a source of health indicators for rare diseases: the ten-year experience of the Veneto Region's rare diseases registry. Orphanet J Rare Dis. 2014;9:37.

6. Franco P. Orphan drugs: the regulatory environment. Drug Discov Today. 2013;18(3-4):163-72.

7. European Organisation for Rare Diseases. Rare diseases: understanding this public health priority. 2005. http://www.eurordis. org/IMG/pdf/princeps_document-EN.pdf. Accessed 10 June 2014.

8. EURORDIS Rare Diseases Europe. Orphan drugs in the United States of America. 2014. http://www.orpha.net/consor/cgi-bin/ Education_AboutOrphanDrugs.php?lng=EN\&stapage=ST_EDUC ATION_EDUCATION_ABOUTORPHANDRUGS_USA. Accessed 13 June 2014.

9. US Government Printing Office Rare Diseases Act. 2002. Accessed 10 June 2014.

10. Commission of the European Communities Rare Diseases: Europe's challenges. 2008. http://ec.europa.eu/health/ph_threats/ non_com/docs/rare_com_en.pdf. Accessed 22 Nov 2014.

11. Harper Government Takes Action to Help Canadians with Rare Diseases. 2012. http://www.hc-sc.gc.ca/ahc-asc/media/nr-cp/_ 2012/2012-147-eng.php. Accessed 10 June 2014.

12. EURORDIS Rare Diseases Europe. National alliances for rare diseases. 2014. http://www.eurordis.org/content/nationalalliances-rare-diseases. Accessed 13 June 2014.

13. Twinning Program. World federation of hemophilia. 2014. http:// www.wfh.org/en/page.aspx?pid=872. Accessed 22 Nov 2014.

14. About CNETS. Carcinoid and Neuroendochrine Tumor Society. 2014. http://www.cnets.org/about.htm. Accessed 22 Nov 2014.

15. Taiwan Foundation for Rare Disorders. Rare diseases in Taiwan. 2014. http://www.tfrd.org.tw/english/rare/cont.php?kind_id=16\&top1=Abo ut\%20rare\%20diseases\&top2=Rare\%20Diseases\%20in\%20Taiwan. Accessed 10 June 2014.

16. Rare Disease and Orphan Drug Act, Taiwan Foundation for Rare Diseases. 2014.

17. Japan Patients Association. About the JPA. 2014. http://www. nanbyo.jp. Accessed 10 June 2014.

18. History Geiser Fundacion. http://www.fundaciongeiser.org/ geiser/historia/?lang=en. Accessed 22 Nov 2014.

19. ALIBER (Alianza Iberoamericana de Enfermedades Poco Frecuentes). http://www.aliber.org. Accessed 22 Nov 2014.

20. Soon S, Lopes G, Lim HW, Wong-Rieger D, et al. A call for action to improve access to care and treatment for patients with rare diseases in the Asia-Pacific region. Orphanet J Rare Dis. 2014; 9(1):137.

21. Korean Organization for Rare Disorders. 2014. http://www.kord.or.kr/\#. Accessed 10 June 2014.

22. Chinese Organization for Rare Disorders. Chinese Organization for Rare Disorders (CORD). 2014. http://chinadolls.org.cn. Accessed 10 June 2014.

23. Rare Disorders Society (Singapore). 2014. http://www.rdss.org. sg. Accessed 10 June 2014.

24. Malaysian Rare Disorders Society. Malaysian Rare Disorders Society. 2014. http://www.mrds.org.my. Accessed 22 Nov 2014. 
25. Philippine Society for Orphan Disorders. Who we are. 2012. http://www.psod.org.ph/about-us/who-we-are/. Accessed 13 June 2014.

26. New Zealand Organisation for Rare Disorders. New Zealand Organisation for Rare Disorders (NZORD). 2013. http://www. nzord.org.nz/. Accessed 10 June 2014.
27. Rare Voices Australia. Rare Voices Australia. 2014. http://www. rarevoices.org.au/. Accessed 10 June 2014.

28. Ride together for better care. Rare Disease Day Thailand. 2014. https://www.facebook.com/rarediseasedaythailand. Accessed 22 Nov 2014. 